\title{
CAMBRIDGE
}

Schur Algebras and Representation Theory

\section{S. MARTIN}

Dr Martin covers the basic ideas of classical Schur algebras and their quantum analogues. He also takes the opportunity to investigate the relationship between Schur algebras and other algebraic structures. This book is the only comprehensive and up-to-date treatment of Schur algebras and their quantum analogues. f30.00 net HB $0521415918 \quad 248$ pp. 1994 Cambridge Tracts in Mathematics 112

\section{Now in paperback}

\section{The Banach-Tarski Paradox}

\section{STAN WAGON}

Asserting that a solid ball may be taken apart into many pieces that can be rearranged to form a ball twice as large as the original, the BanachTarski paradox is examined in relationship to measure and group theory, geometry and logic.

'... this beautiful book is written with care and is certainly worth reading.'

\section{Mathematical Reviews}

'... a readable and stimulating book.'

American Scientist

f15.95 net PB 0521457041253 pp. 1993

\section{Now in paperback}

\section{Designs and their Codes}

\section{E. F. ASSMUS JR. and J. D. KEY}

This is a self-contained and up-to-date account of the applications of algebraic coding theory to the study of combinatorial designs. Whilst the book is aimed at mathematicians working in either coding theory or combinatorics, it is designed to be used by non-specialists and so is of value to graduate students or computer scientists working in those areas.

f17.95 net PB $0521458390 \quad 362$ pp. 1994 Cambridge Tracts in Mathematics 103

\section{Now in paperback \\ Numbers and Functions}

Steps into Analysis

R. P. BURN

The novel approach to rigorous analysis offered here is designed to enable students to grow in confidence and skill and thus overcome their traditional difficulties. Teachers in sixth forms will find that the beginning questions in every chapter provide ways of preparing those at school for university mathematics. Lecturers in universities will be challenged to rethink their conventions about the best way to introduce the central ideas of analysis to undergraduates. f14.95 net PB $0521457734 \quad 352$ pp. 1993

\section{Now in paperback \\ Local Representation Theory}

Modular Representations as an Introduction to the Local Representation Theory of Finite Groups J. L. ALPERIN

$\because$... a beautifully written book. Anyone wishing to learn the fundamental facts of Braucr's theory of blocks cannot do better than to begin his study with this text.'

Bulletin of the London Mathematical Society

f14.95 net PB $052144926 \times 192$ pp. 1993

Cambridge Studies in Advanced Mathematics 11

\section{Computational Algebraic Geometry and Commutative Algebra}

\section{Cortona 1991}

Edited by D. EISENBUD and L. ROBBIANO Includes the most interesting trends and developments in the field, as well as an introduction to the theory of Gröbner bases and their use in computation. Of interest to mathematicians, and to computer scientists interested in symbolic computation. f29.95 net HB $0521442184 \quad 308$ pp. 1993 Symposia Mathematica 34 


\section{Vow in paperback}

\section{inite Group Theory}

\section{ASCHBACHER}

The foundations of the theory of finite groups ire developed in this book. Unifying themes nclude the Classification Theorem and the lassical linear groups. Lie theory appears in hapters on Coxeter groups, root systems, uildings and Tits systems. There is a new proof of the Solvable Signalizer Functor theorem and a srief outline of the proof of the Classification Theorem itself.

:16.95 net PB 0521458269288 pp. 1994 ambridge Studies in Advanced Mathematics 10

\section{Vow in paperback}

\section{5ome Random Series of}

\section{Iunctions}

iecond Edition

\section{-P. KAHANE}

Kahane's book is more like a ramble through ine countryside. At every mile one is rewarded vith a singing waterfall or an old farmhouse, and it virtually every step with a new wayside flower.'

Proceedings of the Edinburgh Mathemetical Society $: 19.95$ net PB $0521456029 \quad 316$ pp. 1993 ambridge Studies in Advanced Mathematics 5

\section{Elementary Probability}

\section{). STIRZAKER}

Elementary Probability provides a simple ntroduction to the theory of probability. This ext contains numerous worked examples and :xercises necessary for problem solving, as well as temonstrates the concepts involved. The topics :overed illustrate the range and power of robability, and include conditional probability, ndependence, random variables, generating unctions, and an introduction to Markov hains.

$: 45.00$ net HB $0521420288 \quad 416$ pp. 1994 $\$ 15.95$ net PB 0521421837

\section{ORDER FORM}

To order please send this form to Tom Peacock at the address below, 'phone 0223325970 or fax 0223315052.

\begin{tabular}{|c|c|c|c|}
\hline Qty & Author & ISBN & Price \\
\hline & & & \\
\hline & & & \\
\hline & & & \\
\hline & & & \\
\hline & & & \\
\hline & & & \\
\hline & & & \\
\hline & & & \\
\hline & & Total & \\
\hline
\end{tabular}

$\square$ I enclose a sterling cheque/eurocheque (payable to Cambridge University Press)

$\square$ Please debit my credit card (Access/Mastercard/ VISA/Amex)* *Please delete as applicable

Card no.

Expiry Date

Signature

Name of cardholder

Address 


\section{Introduction to HOL}

A Theorem-Proving Environment for Higher-Order Logic

Edited by MIKE GORDON and T. F. MELHAM

This book provides a coherent and self-contained introduction to HOL. It succeeds in extracting and compressing from various sources most of the material that is needed for day-to-day work with the system.

E27.95 net Spiral Bound $0521441897 \quad 496$ pp. 1993

\section{Logic Programming}

Operational Semantics and Proof Theory

\section{J. ANDREWS}

Dr Andrews here provides a homogeneous treatment of the semantics of both theoretical and practical logic programming languages. Researchers interested in logic programming or semantics, as well as artificial intelligence search strategies will want to consult this book as the only source for some essential and new ideas in the area.

f25.00 net HB $0521432197 \quad 116$ pp. 1992 Distinguished Dissertations in Computer Science 4

\section{Deduction and Declarative Programming}

\section{P. PADAWITZ}

Here Dr Padawitz emphasises verification based on logical inference rules, i.e. deduction (in contrast to model-theoretic approaches, deductive methods can be automated). His unique treatment captures the actual styles and applications of programming; neirher too general with respect to the underlying logic nor too restrictive for the practice of programming.

f27.95 net HB $0521417236 \quad 288$ pp. 1992

Cambridge Tracts in Theoretical Computer Science 28

\section{Boolean Function Complexity} Edited by M. S. PATERSON

The papers in this book stem from the London Mathematical Society Symposium held at Durham University. The range of topics covered will be of interest to the newcomer to the field as well as the expert, and overall the papers are representative of the research presented at the Symposium.

f22.95 net PB 0521408261216 pp. 1992 London Mathematical Society Lecture Note Series 169

\section{Lectures on Parallel Computation}

Edited by A. GIBBONS and P. SPIRAKIS

The foundations of parallel computation are the concern of this book. Distinguished international researchers have contributed fifteen chapters which togerher form a coherent stream taking the reader who has little prior knowledge of the field to a position of being familiar with leading edge issues. The book may also function as a source of teaching material or reference for researchers.

f25.00 net HB $052141556 \times \quad 448$ pp. 1993

Cambridge International Series on Parallel Computation

\section{Information Dispersal and Parallel Computation}

Y-D. LYUU

In 1989, Michael Rabin proposed a fundamentally new approach to the problems of fault-tolerant routing and memory management in parallel computation, based on the idea of information dispersal. Yuh-Dauh Lyuu develops this idea in a number of new and exciring ways in this extended and updated printing of this $\mathrm{PhD}$ thesis.

f22.95 net HB $052143226 \times 200 \mathrm{pp} .1993$

Cambridge International Series on Parallel Computation

\section{Specification and Proof in Real Time CSP}

JIM DAVIES

The research contained here represents the very latest work on the specification and verification of real-time systems.

f27.95 net HB $0521450551196 \mathrm{pp} .1993$

Distinguished Dissertations in Computer Science 6

\section{An Introduction to Functional Programming Systems Using Haskell \\ ANTONY J. T. DAVIE}

This book serves as an introduction both to functional programming and Haskell. An especially valuable feature are the chapters on programming and implementation, along with large numbers of exercises.

f42.50 net HB $0521258308 \quad 308$ pp. 1992

f14.95 net $P B \quad 0521277248$

Cambridge Computer Science Texts 27

To order or get further information 'phone Tom Peacock on 0223 325782, fax 0223 315052, E mail TW10002@PHX.CAM.AC.UK, or write to the address below. 


\section{INSTRUCTIONS TO AUTHORS}

1 Submission of typescripts

Two copies of the manuscript should be submitted to one of the four Executive Editors (addresses on outside front cover). The editor will acknowledge receipt of the manuscripts. It is important that authors inform the editor of any changes of address whilst their paper is under consideration.

\section{Typescript}

Papers should be typed, double-spaced, on one side only and with generous margins. The pages must be numbered.

The first page should give the title, the author's name and institution, and a short abstract intelligible to mathematicians.

The title, while brief, must be informative (e.g. $A$ new proof of the ergodic theorem, whereas Some applications of a theorem of Birkhoff would be useless).

\section{$3 \quad$ Notation}

It is important that mathematicians expressions are clear to a printer (who is not a mathematician). For instance, $n_{k}(n$ sub $k$ ) is common usage, but avoid if possible using $c$ sub $n$ sub $k$. Fractions are generally best expressed by a solidus. Complicated exponents like

$$
\exp \left\{z^{2} \sin \theta /\left(1+y^{2}\right)\right\}
$$

should be shown in this and no other way.

In the typescript, italics, small capitals and capitals are specified by single, double and triple underlining. Bold-faced types is shown by wavy underlining.

It helps if displayed equations or statements which will be quoted later are numbered in order on the right of their line. They can then be referred to by, for example, 'from (7)'.

The author must enable the printer (if necessary by pencilled notes in the margin) to distinguish between similar symbols such as $o, O, 0,0,0 ; x$, $\mathrm{X}, \mathrm{X} ; \phi, \Phi, \varnothing ; 1,1 ; \varepsilon, \epsilon ; \kappa, k$.

There is no need to underline Greek or script letters provided these are clearly typed. Any special symbols should be explained on a separate sheet of directions for the printer.

If an author wishes to mark the end of the proof of a theorem, the sign $\square$ may be used.

Footnotes should be avoided.

\section{Diagrams}

Figures and drawings should be on separate sheets in black ink. Photocopies are acceptable only if they are as clear as the originals. Symbols, legends and captions should be given on a transparent overlay. Each text figure must be numbered as Figure 1, Figure 2, .. and its intended position clearly indicated in the typescript. The author's name in pencil must be on all separate sheets of diagrams.

A figure is expensive to reproduce and should be included only when the subject matter demands it, or when it greatly clarifies the exposition.

The publisher recognizes that some authors do not have the facilities for producing drawings of a sufficiently high standard to be reproduced directly and is therefore willing to have such diagrams redrawn, provided that they are clear.

\section{Tables}

Tables should be numbered (above the table) and set out on separate sheets. Indicate the position of each in the text as for figures.

6 References

References should be collected at the end of the paper numbered in alphabetical order of the author's names. A reference to a book should give the title, in italics, and then in roman type the publisher's name and the place and year of publication;

[4] N. Dunford \& J. T. Schwartz Linear Operators Part I. Wiley: New York, 1958.

A reference to a paper should give in italics the title of the periodical, the number of the volume and year, and the beginning and end pages of the paper. Titles should be abbreviated as in Mathematical Reviews:

[6] J. E. Littlewood. The 'pits effect' for functions in the unit circle. J. Analyse Math. 23 (1970), 236-268.

\section{Proofs}

Authors receive one set of proofs for correction. If excessive alterations to the original manuscript are requested after the paper has been typeset, the author will be charged the cost of resetting. For papers with more than one author the proofs are sent to the first named author unless the editor receives other instructions. It is important that proofs are corrected and returned promptly.

\section{Reprints}

There are 100 reprints, free of charge, for each paper. For papers with several authors these reprints are divided between the authors. There are no page charges. 


\section{Ergodic theory and dynamical systems}

VOLUME 14 PART 1 MARCH 1994

\section{CONTENTS}

Arteaga, C. Differentiable conjugacy for expanding maps on the circle

Bobok, J. and Kuchta, M. Invariant measures for maps of the interval that do not have points of some period

De Angelis, $V$. Positivity conditions for polynomials

Dumas, H. S., Golse, F. and Lochak, P. Multiphase averaging for generalized flows on manifolds

Fieldsteel, A., del Junco, A. and Rudolph, D. J. $\alpha$-equivalence: a refinement of Kakutani equivalence

Giannoni, F. On the existence of homoclinic orbits on Riemannian manifolds

Glasner, E. On the class of multipliers for $\mathscr{W}^{\perp}$

Huang, $Y$. Ergodic theorems for random sets with density zero

Hurder, S. Topological rigidity of strong stable foliations for Cartan actions

Innami, N. Natural Lagrangian systems without conjugate points

Lin, M. and Wittmann, R. Ergodic sequences of averages of group representations

Rudolph, D. J. A joinings proof of Bourgain's return time theorem 